\title{
Application of Stimstream Shaped Charge with Consistent Entrance Hole and Deep Penetration in Shale Gas Reservoir
}

\author{
Wang Changshuan ${ }^{1, ~ *, ~ G u o ~ H o n g z h i ~}{ }^{2}$, Jiao Guandong ${ }^{1}$, Niu Yuanyuan ${ }^{1}$, Xie Mingzhao ${ }^{1}$ \\ ${ }^{1}$ North Schlumberger Oilfield Technology (Xian) Co., Ltd., Xi'an, China \\ ${ }^{2}$ Schlumberger China S. A., Beijing, China
}

Email address:

wang.changshuan@xtc.slbcn.com (Wang Changshuan)

${ }^{*}$ Corresponding author

\section{To cite this article:}

Wang Changshuan, Guo Hongzhi, Jiao Guandong, Niu Yuanyuan, Xie Mingzhao. Application of Stimstream Shaped Charge with Consistent Entrance Hole and Deep Penetration in Shale Gas Reservoir. American Journal of Applied Scientific Research. Vol. 5, No. 1, 2019 , pp. $21-27$. doi: $10.11648 /$ j.ajasr.20190501.14

Received: February 1, 2019; Accepted: April 1, 2019; Published: April 22, 2019

\begin{abstract}
To address the issues of inefficient hydraulic fracturing on perforation clusters in shale gas horizontal wells caused by the inconsistent size of entrance holes on the casing, Stimstream shaped charge providing consistent hole and deep-penetration was introduced and its special performance was analyzed. Surface concrete target test and field test were conducted respectively to compare the performance between this kind of charge and conventional deep penetration charges made in China. In surface concrete target test, the average hole diameter of Stimstream shaped charge in $0^{\circ}, 90^{\circ}, 180^{\circ}, 270^{\circ}$ phasing is $9.4 \mathrm{~mm}, 9.3 \mathrm{~mm}, 9.3 \mathrm{~mm}, 8.9 \mathrm{~mm}$, the average hole diameter of conventional deep penetration charges in $0^{\circ}, 90^{\circ}, 180^{\circ}$, $270^{\circ}$ phasing is $9.3 \mathrm{~mm}, 8.6 \mathrm{~mm}, 6.5 \mathrm{~mm}, 7.0 \mathrm{~mm}$ respectively. The results shown that Stimstream shaped charge can provide uniform and big holes on the casing regardless of different clearance between perforating gun and casing. In three field testings, comparing the field data of S3406D Stimstream charge and domestic SDP35HMX25 shaped charges, it proven that S3406D can reduce the average hydraulic breakdown pressure by $2044.5 \mathrm{psi}, 1189 \mathrm{psi}$ and $1261.5 \mathrm{psi}$ respectively, and reduce the average treatment pressure to pump proppant by $696 \mathrm{psi}, 652.5 \mathrm{psi}$ and $928 \mathrm{psi}$ respectively. It has remarkable effectiveness on reducing the breakdown pressure and treatment pressure of shale gas formations during hydraulic fracturing operation.
\end{abstract}

Keywords: Shale Gas, Shaped Charge, Consistent Hole, Hydraulic Fracturing, Breakdown Pressure

\section{Introduction}

In recent years, domestic shale gas plays are successfully developed by drilling horizontal wells with cased and cemented wellbore, then performing pump-down perforation and multi-stage hydraulic proppant fracturing stimulation [1]. Customizing horizontal well completions by shifting perforations within a frac stage so that perforation clusters are placed in intervals with similar properties is commonly employed when lateral measurements are available. The lateral is usually grouped into sections based on petrophysical and geomechanically properties: reservoir quality and completion quality, respectively. These engineering approaches have had a positive impact on well productivity [2-5]. Many efforts have been made to improve the effectiveness of horizontal completions as well in China, including well placement in sweet section of shale gas reservoir and geoengineering approach for optimizing the design for frac stages breakdown and perforation cluster placement [6-9]. However, these studies ignore that the tradition perforation system with deep-penetration charge is not optimized for hydraulic fracturing in horizontal well completions, and inconsistent perforation hole size caused higher initiation pressure and failure to stimulate the formation sometimes. Studies from production logging data have shown that many perforation clusters are not producing fluids after stimulation [10-11].

Perforation is a necessary process before fracturing stimulation in shale gas well, which creates the communication channel between wellbore and formation, and opens shale gas flow passages. The perforation holes are not only the passage of oil and gas flow, but also the inlet of the fracturing proppant and fluid for hydraulic fracturing. By 
studying the pressure loss law of fracturing fluid through the perforation hole, Jiang MZ and Behrmann, L. A believes that, the friction resistance of the holes on casing, it's very important factor to hydraulic proppant fracturing, the larger the hole diameter is, the smaller the pressure drops. Usually, the hole diameter is required 6 to 10 times of the size of proppant to prevent the bridge plugging [12-15]. Therefore, it is critical to maintain consistent perforation hole size in different phasing around the casing.

However, the perforating gun lies on the down side of the casing in the shale gas horizontal well, and it cannot be centered, so the size of the perforation holes on the casing are inconsistent, and the holes close to the casing are large, and the holes away from the casing are small. Therefore, for hydraulic fracturing operation in tight formation with high breakdown pressure, it becomes very difficult and the operation cost will be high $[12,16]$. In order to improve the effectiveness of hydraulic fracturing and solve the problem of inconsistent perforating entrance holes under the condition that perforation gun is not centered in the casing, Schlumberger introduced Stimstream shaped charge that can provide consistent holes and deep penetration, the perforation hole diameter on the casing is not affected by the clearance between the perforating gun and the downhole casing. It has been widely used in shale gas wells in North America, and it has remarkable effects on reducing the breakdown pressure and treatment pressure of formations. In order to meet the needs of improving the development efficiency of tight shale gas wells, Stimstream shaped charges with consistent hole and deep penetration were imported for ground concrete target test and field test in China. Good application results were achieved, and it has important guiding significance for improving the perforation completion technology for shale gas exploration and development in China.

\section{Stimstream Shaped Charge Configuration Features}

The general-purpose shaped charges are mainly composed of primary explosive, main explosive, liner, and metal case (see Figure 1).

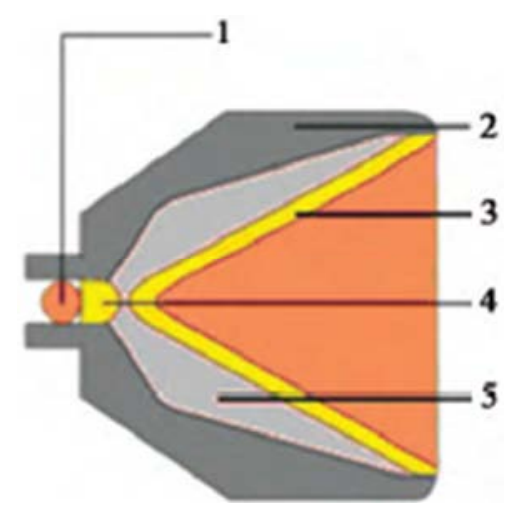

Figure 1. Configuration of shaped charge.

(1- detonating cord; 2 - case; 3 - shaped charge liner; 4 - primary explosive; 5 - main explosive)
The liner is the core component of the shaped charge, which has a huge influence on the jet velocity and jet density. Different liner configuration will produce different perforation effects. For example, the single-cone liner with variable wall thickness can achieve deep penetration effect and the hornshape liner structure can achieve big hole effect. According to the quasi-steady incompressible fluid mechanics theory, the perforation depth of the shaped charge has the following relationship with the jet velocity [17-18]:

$$
L=(H-b)\left[\left(\frac{v_{j 0}}{v_{j}}\right)^{\sqrt{\frac{\rho_{j}}{\rho_{t}}}}-1\right]
$$

In equation (1): $\mathrm{L}$ is the perforation depth; $\mathrm{v}_{\mathrm{j} 0}$ is the jet head velocity; $v_{j}$ is the jet tail velocity; $\rho_{t}$ is the target density; $\rho_{\mathrm{j}}$ is the jet density; $\mathrm{H}$ is the clearance; $\mathrm{b}$ is a constant.

The domestic made $25 \mathrm{~g}$ explosive-loading shaped charge is generally designed with a cone-shaped configuration. It is used with $89 \mathrm{~mm}$ perforator in vertical well, the penetration can normally reach $600 \mathrm{~mm}$ to $800 \mathrm{~mm}$ and the hole diameter is approximative 9.0 to $9.5 \mathrm{~mm}$. Its design does not consider the problem that perforating gun is eccenetered on the casing in the horizontal well, it will cause the hole diameter in some phasing to become smaller. If the liner is designed with multi-section combination of tapered and curved shape and variable wall thickness, it will form a linear to nonlinear wall thickness variation structure along the axial direction, which improves the head speed of the jet and makes it thicker [19]. The Stimstream shaped charge changes the jet head speed and its thickness through special design such as the liner geometry, so the jet penetration hole diameter is hardly affected by the variation of clearance and within a certain range, which improves the entrance hole uniformity and increases the penetration depth.

\section{API RP19B Concrete Target Test}

In order to evaluate the perforation entrance hole of the Stimstream shaped charge and the penetration effect in sandstone target, two standard concrete targets with size of $\Phi 2200 \mathrm{~mm} \times 1400 \mathrm{~mm}$ were simultaneously built according to the requirements of Section 1 of API RP19B, and solidified for 28 days; casings were $1.5 \mathrm{~m}$ long and 5.5 " (139.7mm) outer diameter, wall thickness $12.7 \mathrm{~mm}$, inner diameter $114.3 \mathrm{~mm}, \mathrm{P} 110$ grade steel. The compressive strength of the two concrete targets is $6452.5 \mathrm{psi}$ that measured before shoot test.

The perforating guns used in the test have an outer diameter of $3.5^{\prime \prime}$, shoot density of 16 each holes per meter, phasing of $90^{\circ}$, nominal length of $1 \mathrm{~m}$. The domestic made shaped charge is SDP35HMX25 (outer diameter $35 \mathrm{~mm}$, explosive loading 25g) and Stimstream shaped charge is S3406D RDX (outer diameter 36mm, explosive loading 25g), tested charges are randomly selected from same one batch, as shown in Figure 2. The two perforators are assembled with $0^{\circ}$-phasing close to the inner wall of the casing, the minimum 
clearance between the gun and the casing is $0 \mathrm{~mm}$, and the maximum clearance is $25.3 \mathrm{~mm}$, as shown in Figure 3. This test was conducted with two different shaped charges in same type of $89 \mathrm{~mm}$ gun, same shoot density, same casing, and same strength of concrete target, comparing what effect of variable clearance to the casing affects perforation hole size around casing and penetration depth into the concrete target.
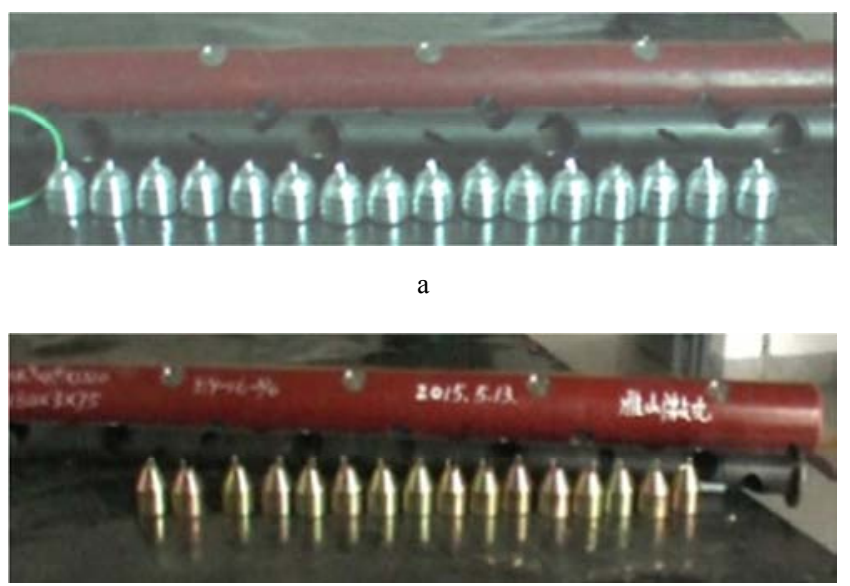

b

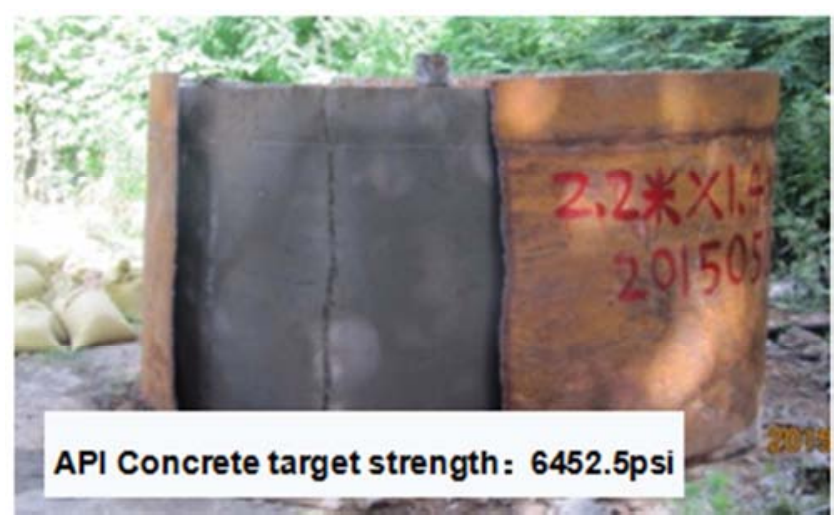

c

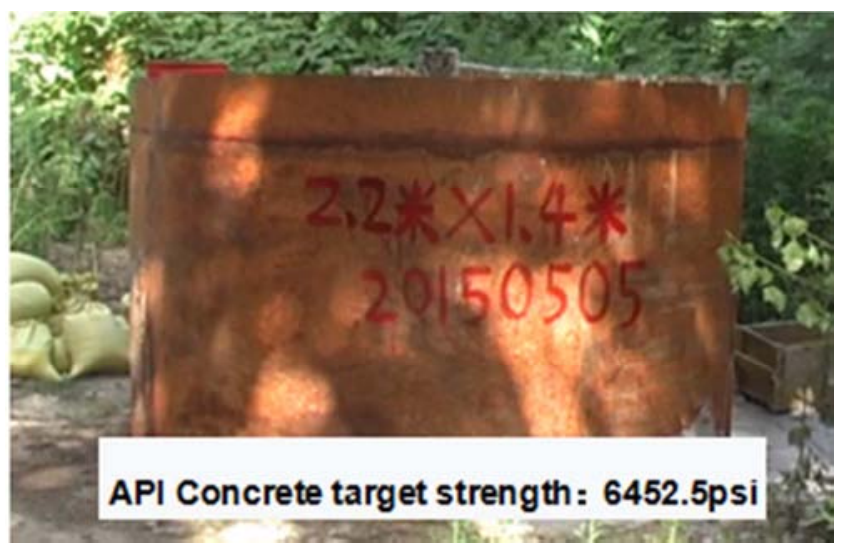

d

Figure 2. Concrete target setup for two kinds of charges.

a. Shaped charge of SDP35HMX25 and carrier. b. shaped charge of S3406D RDX and carrier. c. API concrete target for SDP35HMX25 test, d. API concrete target for S3406D RDX test

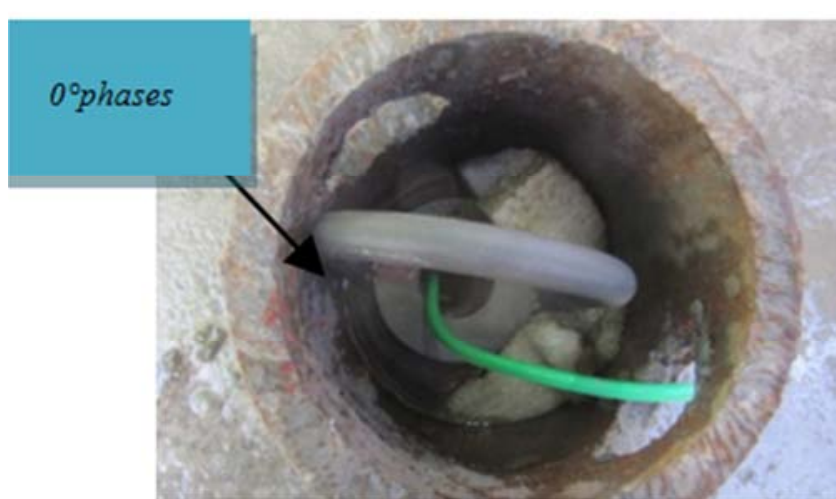

a

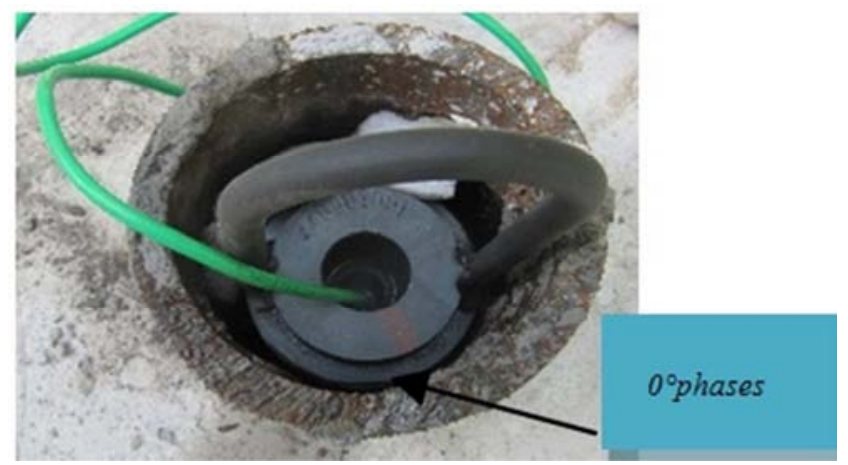

b

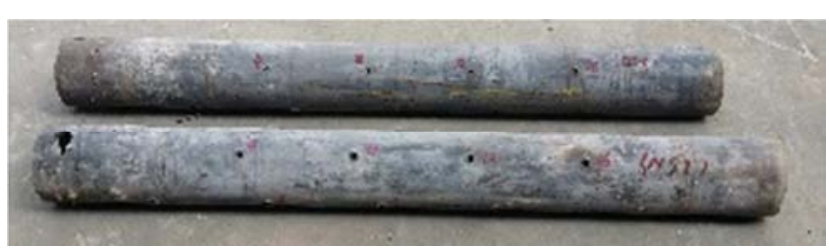

c

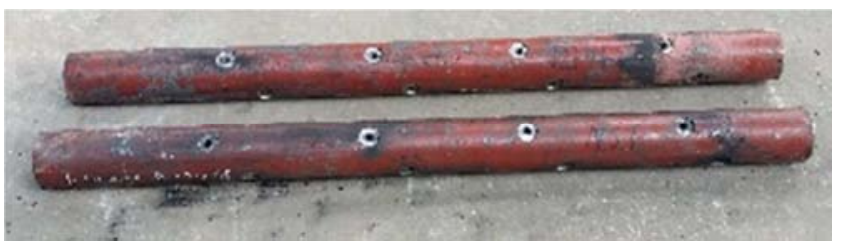

d

Figure 3. Two kinds of perforators eccentrally setup in casing.

a. gun load with SDP35HMX25 charge. b. gun load with S3406D RDX charge. c. $5.5^{\prime \prime}$ casings after the tests. d. $89 \mathrm{~mm}$ OD perforation guns after the tests.

After the perforation guns are detonated, the concrete targets are cut along the crack of the four phasing, and the perforation effect of different charges is shown in Figure 4 and Figure 5. Measuring the hole diameter around the casing and the penetration depth into the concrete target can directly compare the difference of performance between the domestic and imported shaped charges. Table 1 shows the average penetration depth of the concrete targets at the $0^{\circ}, 90^{\circ}, 180^{\circ}$ and $270^{\circ}$ phasing of the two kinds of charges. Table 2 shows the average perforation diameter around the casing for the 
two kinds of charges at $0^{\circ}, 90^{\circ}, 180^{\circ}$ and $270^{\circ}$, respectively.
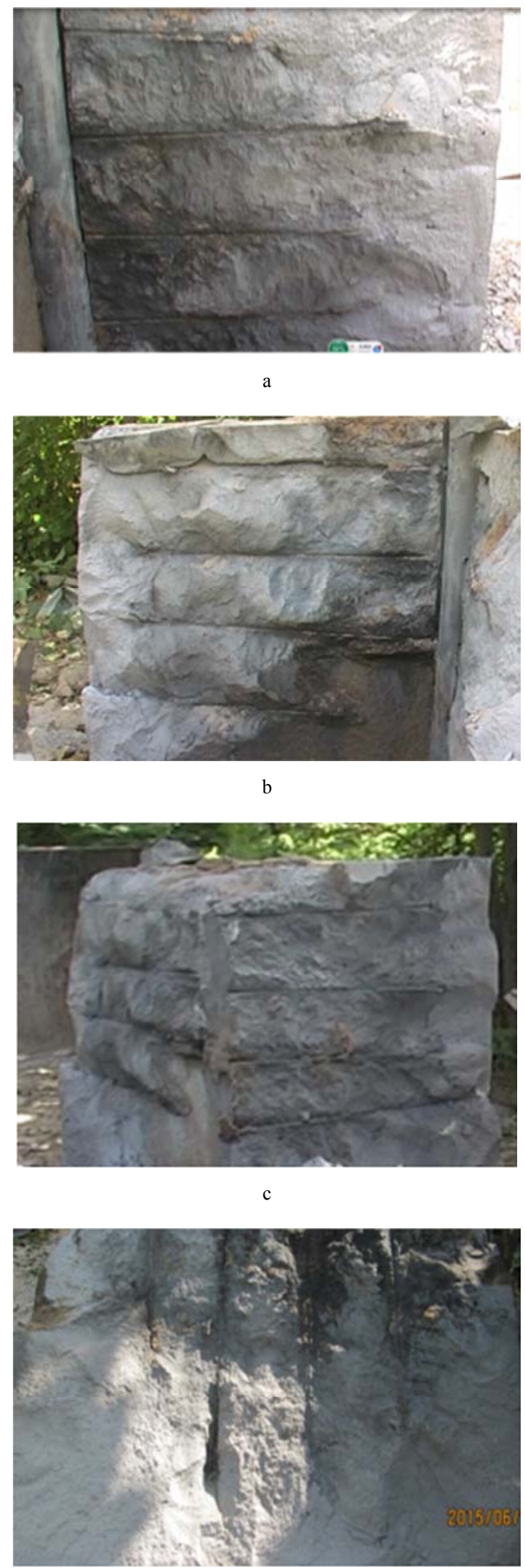

d

Figure 4. Concrete target after test for SDP35HMX25 charges, sliced in direction of phasing $0^{\circ}(\mathrm{a}), 90^{\circ}(\mathrm{b}), 180^{\circ}(\mathrm{c})$ and $270^{\circ}(\mathrm{d})$ respectively.

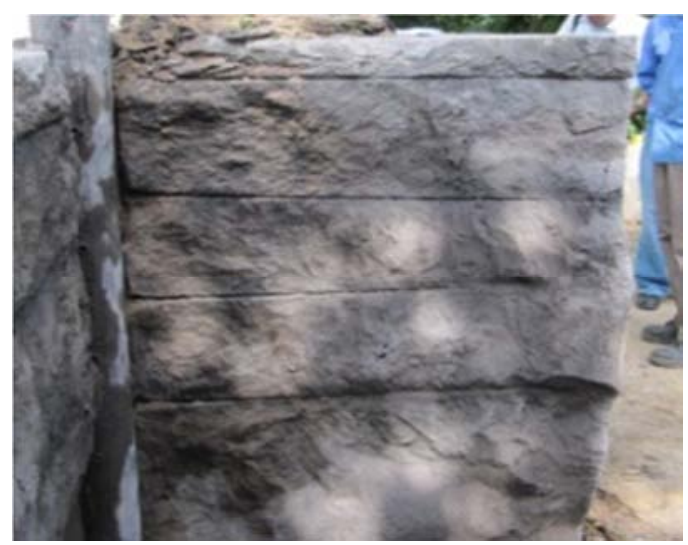

a

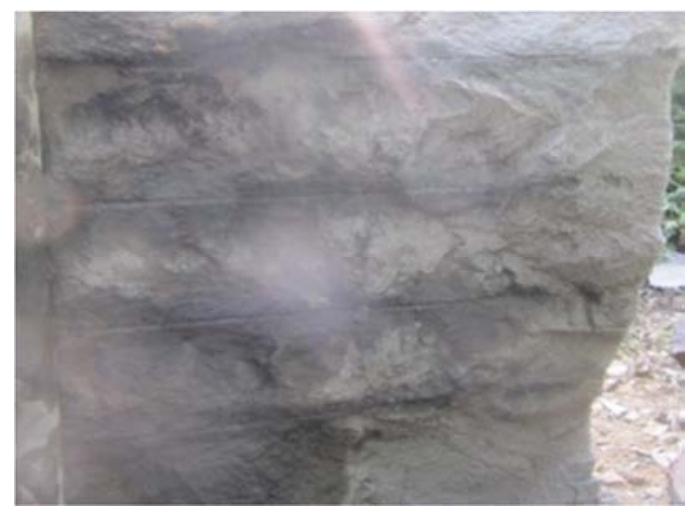

b
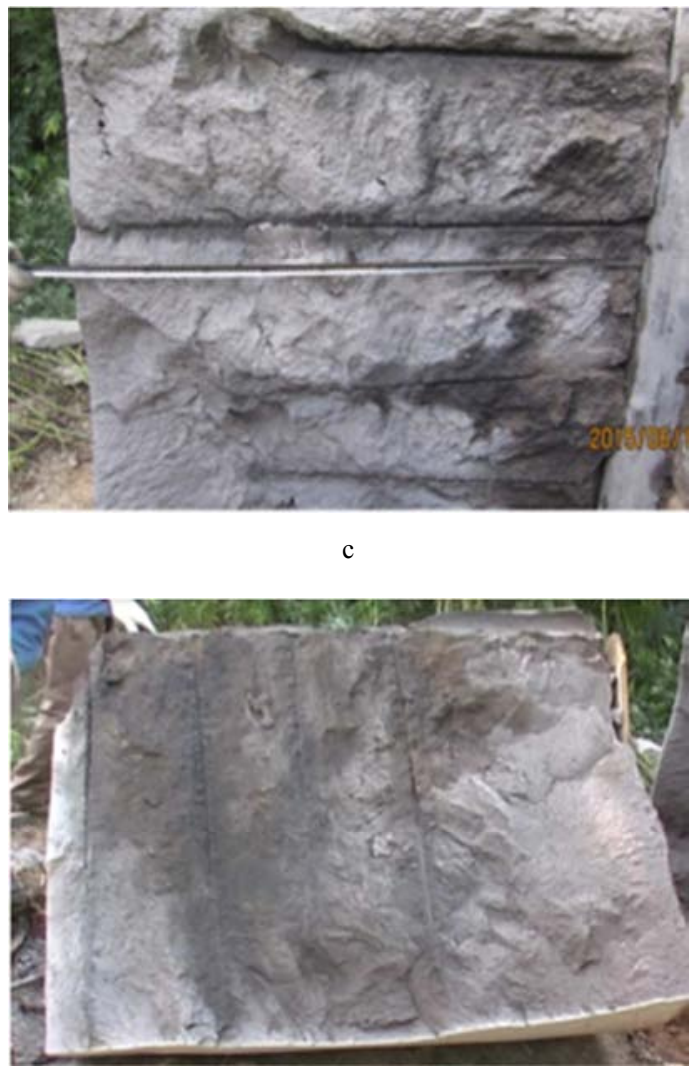

d

Figure 5. Concrete target after test for $S 3406 D$ charges, sliced in direction of phasing $0^{\circ}($ a $), 90^{\circ}(\mathrm{b}), 180^{\circ}(\mathrm{c})$ and $270^{\circ}(\mathrm{d})$ respectively. 
Table 1. Penetration depth of different charges at different phasing.

\begin{tabular}{|c|c|c|}
\hline $\begin{array}{ll} & \text { Depth } \\
\text { Phasing } & \end{array}$ & SDP35HMX25 (mm) & S3406D RDX (mm) \\
\hline $0^{\circ}$ & 878 & 957 \\
\hline $90^{\circ}$ & 876 & 812 \\
\hline $180^{\circ}$ & 777 & 948 \\
\hline $270^{\circ}$ & 679 & 736 \\
\hline Average & 803 & 863 \\
\hline
\end{tabular}

Table 2. Perforating hole size of different charges at different phasing.

\begin{tabular}{|c|c|c|}
\hline Phasing Diameter & SDP35HMX25 (mm) & S3406D RDX (mm) \\
\hline $0^{\circ}$ & 9.3 & 9.4 \\
\hline $90^{\circ}$ & 8.6 & 9.3 \\
\hline $180^{\circ}$ & 6.5 & 9.3 \\
\hline $270^{\circ}$ & 7.0 & 8.9 \\
\hline Average & 7.9 & 9.2 \\
\hline
\end{tabular}

It shown the appearance of casing perforation holes of two kinds of charges with same phasing and same clearance respectively from Figure 6 to Figure 9. It observed that SDP35HMX25 charge and S3406D RDX charge with zero clearance between perforation gun and casing in $0^{\circ}$ phasing, hole diameter is $9.3 \mathrm{~mm}$ and $9.4 \mathrm{~mm}$ respectively, but in $180^{\circ}$ phasing with maximum clearance $(25.3 \mathrm{~mm})$, the average hole diameter is $6.5 \mathrm{~mm}$ and $9.3 \mathrm{~mm}$ respectively. The uniformity of perforation hole diameter of S3406D RDX charge is much better than that of SDP35HMX25 charge.
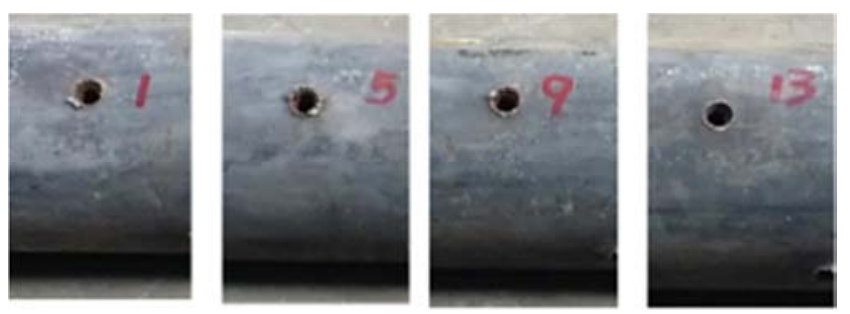

a
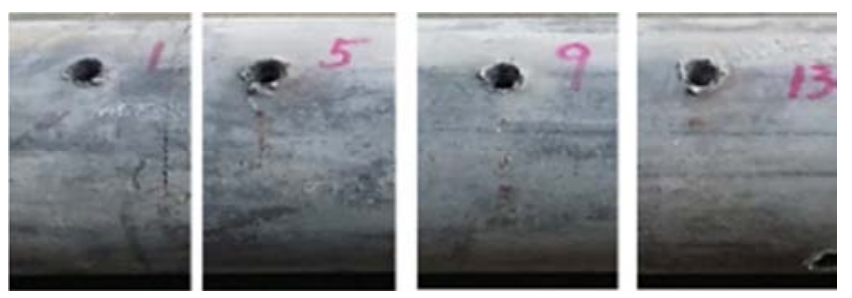

b

Figure 6. Casing entrance holes of two kinds of charges at $0^{\circ}$ phasing.

a. hole diameter $9.3 \mathrm{~mm}$ from SDP35HMX25 charge. b. hole diameter $9.4 \mathrm{~mm}$ from S3406D RDX charge.
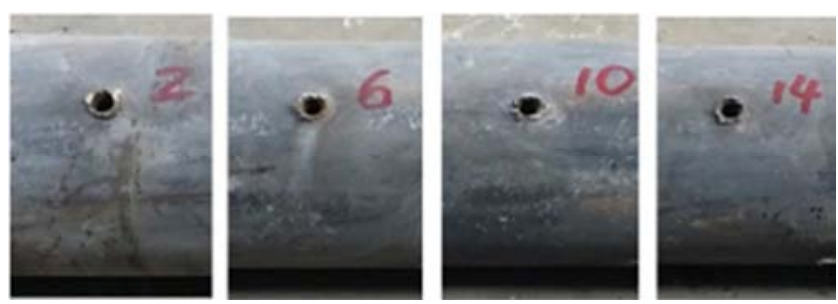
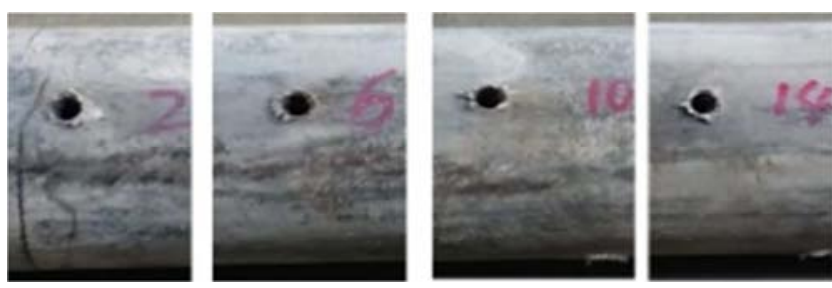

b

Figure 7. Casing entrance holes of two kinds of charges at $90^{\circ}$ phasing.

a. hole diameter $8.6 \mathrm{~mm}$ from SDP35HMX25 charge. b. hole diameter $9.3 \mathrm{~mm}$ from S3406D RDX charge.
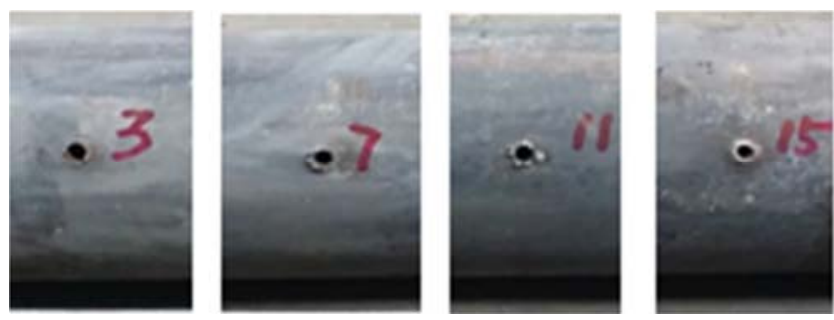

a
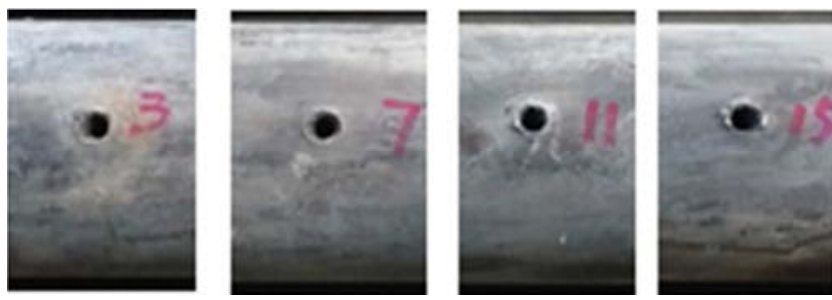

b

Figure 8. Casing entrance holes of two kinds of charges at $180^{\circ}$ phaseing.

a. hole diameter $6.5 \mathrm{~mm}$ from SDP35HMX25 charge. b. hole diameter $9.3 \mathrm{~mm}$ from S3406D RDX charge.
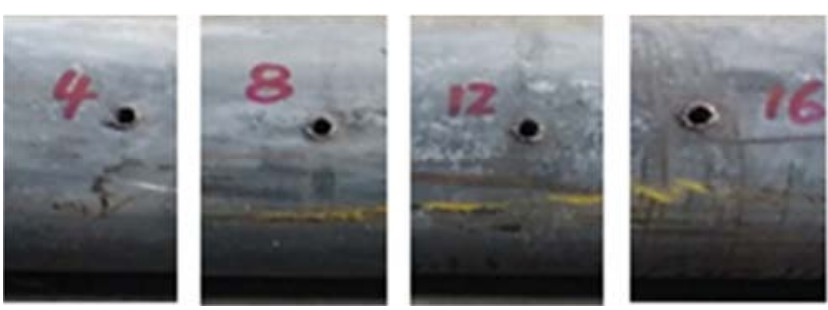

a
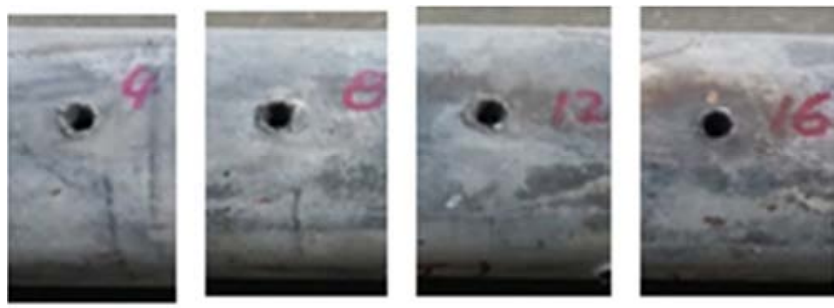

Figure 9. Casing entrance holes of two kinds of charges at $270^{\circ}$ phasing.

a. hole diameter $7.0 \mathrm{~mm}$ from SDP35HMX25 charge. b. hole diameter $8.9 \mathrm{~mm}$ from S3406D RDX charge. 


\section{Oilfield Trial Results and Analysis}

Gongxian county is located in the core intersection of "Sichuan Changning-Weiyuan National Shale Gas Demonstration Zone" and "Dianqianbei Zhaotong National Shale Gas Demonstration Zone", where abundant shale gas resource is estimated. Some of wells encountered problem of formation with high breakdown pressure is difficult for hydraulic fracturing treatment in the earlier stage of exploration and development. In order to solve the practical difficulties, Pad H1 and Pad H6 were selected for the field trial to evaluate the performance of two kinds of perforation charges. Table 3, Table 4, and Table 5 are the detail data of breakdown pressure and treatment pressure that are recorded during hydraulic fracturing operation in different wells on the same pad or different fracturing stages in the same well using SDP36HMX25 ultra-deep penetration charge and S3406D Stimstream shaped charge.

Table 3. Breakdown pressure after Pump-down perforation on shale gas H1 Pad (Same pad, different wells, and different charges).

\begin{tabular}{|c|c|c|c|c|c|c|}
\hline Number & Well & $\begin{array}{l}\text { Breakdown pressure } \\
\text { (psi) }\end{array}$ & $\begin{array}{l}\text { Average breakdown } \\
\text { pressure (psi) }\end{array}$ & $\begin{array}{l}\text { Treatment pressure } \\
\text { (psi) }\end{array}$ & $\begin{array}{l}\text { Average treatment } \\
\text { pressure (psi) }\end{array}$ & Shaped charge \\
\hline 1 & YH1-3 STAGE 3 & 12180 & \multirow{5}{*}{12267} & 11165 & \multirow{5}{*}{11252} & SDP35HMX25 \\
\hline 2 & YH1-3 STAGE 6 & 12035 & & 11310 & & SDP35HMX25 \\
\hline 3 & YH1-3 STAGE 12 & 11890 & & 10585 & & SDP35HMX25 \\
\hline 4 & YH1-5 STAGE 5 & 12470 & & 11600 & & SDP35HMX25 \\
\hline 5 & YH1-5 STAGE 13 & 12760 & & 11600 & & SDP35HMX25 \\
\hline 6 & YH1-2STAGE 1 & 9280 & \multirow{9}{*}{10222.5} & 8700 & \multirow{9}{*}{9106} & S3406D RDX \\
\hline 8 & YH1-4 STAGE 2 & 10875 & & 10150 & & S3406D RDX \\
\hline 9 & YH1-4 STAGE 8 & 10585 & & 8265 & & S3406D RDX \\
\hline 10 & YH1-4 STAGE 19 & 9135 & & 7830 & & S3406D RDX \\
\hline 11 & YH1-6 STAGE 2 & 10585 & & 9425 & & S3406D RDX \\
\hline 12 & YH1-6 STAGE 7 & 9280 & & 8410 & & S3406D RDX \\
\hline 13 & YH1-8 STAGE 1 & 11310 & & 10440 & & S3406D RDX \\
\hline 14 & YH1-8 STAGE 7 & 10585 & & 9570 & & S3406D RDX \\
\hline 15 & YH1-8 STAGE 19 & 9715 & & 8845 & & S3406D RDX \\
\hline
\end{tabular}

Table 4. Breakdown pressure after Pump-down perforation on shale gas H6 Pad (Same pad, different wells, and different charges).

\begin{tabular}{|c|c|c|c|c|c|c|}
\hline Number & Well & $\begin{array}{l}\text { Breakdown } \\
\text { pressure (psi) }\end{array}$ & $\begin{array}{l}\text { Average breakdown } \\
\text { pressure (psi) }\end{array}$ & $\begin{array}{l}\text { Treatment } \\
\text { pressure (psi) }\end{array}$ & $\begin{array}{l}\text { Average treatment } \\
\text { pressure (psi) }\end{array}$ & Shaped charge \\
\hline 1 & YSH6-1 STAGE 3 & 11745 & \multirow{7}{*}{11382.5} & 10005 & \multirow{6}{*}{9686} & SDP35HMX25 \\
\hline 2 & YSH6-1 STAGE 20 & 11455 & & 8700 & & SDP35HMX25 \\
\hline 3 & YSH6-3 STAGE 1 & 11455 & & 10150 & & SDP35HMX25 \\
\hline 4 & YSH6-3 STAGE 14 & 11020 & & 10150 & & SDP35HMX25 \\
\hline 5 & YSH6-5 STAGE 5 & 11310 & & 9425 & & SDP35HMX25 \\
\hline 6 & YSH6-5 STAGE 12 & 11310 & & 9715 & & SDP35HMX25 \\
\hline 7 & YSH6-7 STAGE 10 & 10440 & & 9425 & \multirow{3}{*}{9033.5} & S3406D RDX \\
\hline 8 & YSH6-7 STAGE 14 & 9715 & \multirow[t]{2}{*}{10193.5} & 8990 & & S3406D RDX \\
\hline 9 & YSH6-7 STAGE 20 & 10440 & & 8700 & & S3406D RDX \\
\hline
\end{tabular}

Table 5. Breakdown pressure after Pump-down perforation on shale gas H6 Pad (Same pad, same well, and different stages, different charges.

\begin{tabular}{|c|c|c|c|c|c|c|}
\hline Number & Well & $\begin{array}{l}\text { Breakdown pressure } \\
\text { (psi) }\end{array}$ & $\begin{array}{l}\text { Average breakdown } \\
\text { pressure (psi) }\end{array}$ & $\begin{array}{l}\text { Treated pressure } \\
\text { (psi) }\end{array}$ & $\begin{array}{l}\text { Average treated } \\
\text { pressure (psi) }\end{array}$ & Shaped charge \\
\hline 1 & YSH6-7 STAGE 1 & 12325 & \multirow{3}{*}{11455} & 10875 & \multirow{3}{*}{10585} & SDP35HMX25 \\
\hline 2 & YSH6-7 STAGE 2 & 10150 & & 10150 & & SDP35HMX25 \\
\hline 3 & YSH6-7 STAGE 3 & 11890 & & 10875 & & SDP35HMX25 \\
\hline 4 & YSH6-7 STAGE 10 & 10440 & \multirow{3}{*}{10193.5} & 9425 & \multirow{3}{*}{9657} & S3406D RDX \\
\hline 5 & YSH6-7 STAGE 14 & 9715 & & 9715 & & S3406D RDX \\
\hline 6 & YSH6-7 STAGE 20 & 10440 & & 9860 & & S3406D RDX \\
\hline
\end{tabular}

Comparing the field test data of S3406D Stimstream charge and domestic SDP35HMX25 shaped charges, it proven that S3406D can reduce the average hydraulic breakdown pressure by 2044.5 psi and the average treatment pressure to pump proppant by 696psi in $\mathrm{Pad} \mathrm{H1}$, it can reduce the average breakdown pressure by 1189 psi and the average treatment pressure by $652.5 \mathrm{psi}$ respectively in Pad H6. It reduced the average breakdown pressure by $1261.5 \mathrm{psi}$ and the average treatment pressure by 928 psi with S3406D charge comparing to SDP35HMX25 shaped charges in different fracturing stages in well YSH6-7.

Although the difference of penetration depth between the two kinds of shaped charges in surface concrete targets test is not obvious, however the perforating operation for field trial is in horizontal wells of shale gas where the perforating gun cannot be centered in the wellbore due to gun's gravity. Because of the variation of the clearance between the perforating gun and the casing, in additional of the presence of the fluid medium, it will inevitably lead to a velocity difference of the shaped jet colliding to the casing for SDP36HMX25 shaped charge and result in 
inconsistent hole size around the casing. It consequently caused that high pumping pressure has to be applied to breakdown the formation or to pump proppant/fluid into formation during hydraulic fracturing operation as field test data proved. However, the latest S3406D shaped charges utilizes a variable wall thickness liner with a combination of cone-shape and curved-shape, which improves the head speed of the jet and makes it thicker. Therefore, there is very little variation in terms of entrance hole size although the distance between the perforating gun and the casing varies significantly. The field test results confirmed that it brings obvious benefit to reduce breakdown pressure and proppant injection pressure during hydraulic fracturing operation.

\section{Conclusions}

Shooting test results with ground concrete target shown that Stimstream shaped charge can achieve size-consistency holes in each phasing even though the perforating gun is not centered, it realized perfect combination of consistent entrance hole and deep penetration. The perforation effect in horizontal wells of shale gas is confirmed that the breakdown pressure and pumping pressure are significantly reduced by use of Stimstream charges, and it leads to efficient and smooth hydraulic fracturing operation. Stimstream shaped charges has remarkable effect on reducing breakdown pressure and treatment pressure in complex downhole conditions such as high formation stress and high fracturing treatment pressure in deep horizontal wells in unconventional shale gas, coalbed methane, tight oil and gas. It has bright application prospect.

\section{References}

[1] MA C Q. Shale Gas Wells Fracturing Technology and Its Effect Evaluation [J]. Petrochemical Industry and Application, 2011, 30(5): $1-3$.

[2] Cipolla, C., Weng, X., Onda, H., Nadaraja, T., Ganpuly, U. and Malpani, R. 2011. New Algorithms and Integrated Workflow for Tight Gas and Shale Completions. Paper SPE 146872 presented at the SPE Annual Technical Conference and Exhibition, Denver, Colorado, USA, 30 October - 2 November 2011.

[3] Walker, K., Wutherich, K., Terry, J., Shreves, J. and Caplan, J. 2012. Improving Production in the Marcellus Shale Using an Engineered Completion Design: A Case Study. Paper SPE 159666 presented at the SPE Annual Technical Conference and Exhibition, San Antonio, Texas, USA, 8 - 10 October 2012.

[4] Slocombe, R., Acock, A., Chadwick, C., Wigger, E., Viswanathan, A., Fisher, K. and Reischman, R. 2013. Eagle Ford Completion Optimization Strategies Using Horizontal Logging Data. Paper URTeC 1571745 presented at the Unconventional Resources Technology Conference, Denver, Colorado, USA, 12 - 14 August 2013.

[5] George Waters and Xiaowei Weng. The Impact of Geomechanics and Perforations on Hydraulic Fracture Initiation and Complexity in Horizontal Well Completions. SPE 181684. Presented at the SPE Annual Technical Conference and Exhibition held in Dubai, UAE, 26-28 September 2016.
[6] Wu Qi, Liang Xing, Xian Chenggang et al. 2015. Geoscience-to-Production Integration Ensures Effective and Efficient South China Marine Shale Gas Development. China Petroleum Exploration 20 (4): 1-23.

[7] Wu Kun-yu, Zhang Ting-shan, Yang Yang et al. 2016. Geological Characteristics of Wufeng-Longmaxi shale-gas reservoir in the Huangjingba Gas Field, Zhaotong National Shale Gas Demonstration Area. Geology in China 43 (1): 275 287.

[8] Liang Xin, Wang Gaocheng, Xu Zhengyu, et al, Comprehensive evaluation technology for shale gas sweet sports in the complex marine mountains, South China: A case study from Zhaotong national shale gas demonstration zone [J], NATRUAL GAS INDUSTRY, 201636 (1) : 33 - 42.

[9] Liang Xing, Wang Lizhi, Zhang Jiehui et al. 2015. An Integrated Approach to Ensure Horizontal Wells 100\% in the Right Positions of the Sweet Section to Achieve Optimal Stimulation: A Shale Gas Field Study in the Sichuan Basin, China. SPE-177474. Presented at the Abu Dhabi International Petroleum Exhibition and Conference, Abu Dhabi, UAE, 9-12 November 2015.

[10] Wang Weixu, Xian Chenggang, Liang Xing, et al. 2017. Production Controlling Factors of the Longmaxi Shale Gas Formation - A Case Study of Huangjingba Shale Gas Field. SPE186874. Presented at the SPE/IATMI Asia Pacific Oil \& Gas Conference and Exhibition held in Jakarta, Indonesia, 17-19 October 2017.

[11] Miller, C., Waters, G. and Rylander, E. 2011. Evaluation of Production Log Data from Horizontal Wells Drill in Organic Shales. Paper SPE 144326 presented at the SPE North American Unconventional Gas Conference \& Exhibition, The Woodlands, Texas, USA, 12 - 16 June 2011.

[12] JIANG M Z, CAO Y P, YE P et al. Study on Pressure Loss of Fracturing Fluid at Bullet Hole [J]. Oil Field Equipment, 2011, $40(3): 1-4$.

[13] Behrmann, L. A. and Elbel, J. L. 1991. Effect of Perforations on Fracture Initiation. JPT (May, 1991) pp 608 - 615.

[14] Behrmann, L. A. and Nolte, K. G. 1998. Perforating Requirements for Fracture Stimulations. Paper SPE 39453 presented at the SPE International Symposium on Formation Damage Control, Lafayette, Louisiana, USA, 18 - 19 February 1998.

[15] C. Gresbeck , R. E. Collins. Particle Transport Through Perforations. Society of Petroleum Engineers Journal, December $1982: 857-865$

[16] CUI S H, BAN F S, YUAN G J. Shale Gas Drilling and Completion Technology Present Situation and Difficulty Analysis [J]. NATURAL GAS INDUSTRY. 2011, 31 (4): 72-75.

[17] WANG S L, DONG K X, DONG H Y. Effect analysis of perforating parameters upon initiation pressure in low permeability reservoir [J]. Oil Drilling and Production Technology, 2009, 31(3): 85-89.

[18] Eight Department of Beijing Industrial Institute, Explosion and its role (Volume two) [M] . BeiJing: National Defense Industry Press, 1979: 95-110.

[19] GAO Y H, GU X H, WANG F Y. Powder liner density effect on the performance of shaped charge jet $[\mathrm{J}]$. Chinese Journal of High Pressure Physics, 2013, 27(4): 556-560. 